\title{
Research and evaluation on the development of competitive sports in
}

\section{Liaoning Province}

\author{
Le Wang ${ }^{1, a}$ \\ ${ }^{1}$ P.E.Department of Dalian Ocean University, 116023 \\ ${ }^{a}$ email
}

Keywords: Competitive Sports, Liaoning Province, Evaluation

\begin{abstract}
The development of competitive sports should be based on the existing social and economic conditions, and based on a new round of the Olympic cycle, deepen the reform of competitive sports system; to define the rights and responsibilities of the development of competitive sports, improve the organizational structure and operational mechanism of the development of competitive sports. (2)Research on the coordinated development of "two strategies": To change the concept, fully aware of the dialectical unity between the "two strategies", should always adhere to the people-oriented principle, develop good health habits, enhanced sense of lifelong physical training, to lay a solid foundation for the development of athletic sports
\end{abstract}

\section{Introduction}

The sports development in Liaoning province has obvious lag characteristic, make a lot of "take precautions after suffering a loss" style of behaviour. This is the result of the comprehensive factors of reality. The sports development of Liaoning province is a systematic project, and are closely linked with competitive sports, mass sports and school sports are closely linked. If poor contact with each other, it is easy to cause all kinds of problems. The phenomenon of "landslide" in the development of sports in Liaoning province is mainly caused by the imperfect competitive system and the training of reserve talents which is provides a clear direction for future development. The sports development in Liaoning province must get down to basics. It can work hard on sustainable development in the development of the project, the input and output of funds, competitive sports management and reserve personnel. And adhere to the "province standarised", Make new development strategy, implement new development policy, realize the leap forward development of sports in our province.

Theoretical Research

In the new period, the reform and rejudgement of the strategic goal of the development of competitive sports in Liaoning province. It will be influenced by the national sports power forward strategy to a great extent. Because, the national strategy not only represents our country's national interests, but also symbolizes the comprehensive strength of our country, is also an important basis for the development of competitive sports in Liaoning Province. (1)Research on the development strategy of competitive sports: The development of competitive sports should be based on the existing social and economic conditions, and based on a new round of the Olympic cycle, deepen the reform of competitive sports system; to define the rights and responsibilities of the development of competitive sports, improve the organizational structure and operational mechanism of the development of competitive sports. (2)Research on the coordinated development of "two strategies": To change the concept, fully aware of the dialectical unity 
between the "two strategies", should always adhere to the people-oriented principle, develop good health habits, enhanced sense of lifelong physical training, to lay a solid foundation for the development of athletic sports. (3) A research on the reform and perfection of the whole nation system of competitive sports: To adjust the goal, direction and strategy of the development of competitive sports under the system of the whole nation, to realize the scientific development and overall development of competitive sports in the whole nation system; To correctly deal with the relationship between the Olympic Games and non Olympic events, and to achieve the coordinated development of competitive sports.

In summary, the above research deeply reflects the different views of different scholars on China's competitive sports development issues. There are great inspiration and help to content-rich, clear point of view, profound thinking to fully understand the development history and present situation of competitive sports, explain the contradiction, and to explore the ideas and direction of future development. According to the theory of sociology, the current situation of competitive sports in Liaoning Province, the development strategy of competitive sports as the research object, based on field research. On the basis of the analysis of the present situation of Liaoning province's sports project setting, reserve personnel training, fund investment and management, By combining quantitative and qualitative analysis, and the theory and effect, static and dynamic method, the developing strategy of the promotion of Liaoning Province from a big province of the tournament athletics to factors related to the transformation of sports province for empirical research, and accordingly seek competitive sports in Liaoning province goal to achieve slightly

\section{Analysis of Present Competitive Sports of Liaoning Province}

Province of Liaoning province as sports, the competitive sports remained prosperous, and always in the forefront in the Olympic Games medal contribution rate. In the national and world competitive arena, Liaoning athlates have super strenth in the gold medal or medal. In recent years, Liaoning province has also assumed the task of transporting sports talents for the country and other provinces, in promoting the role of competitive sports in China. Taking Olympic Games, for example, from the 23rd Olympic Games in Los Angeles to the 30th London Olympic Games, our nation obtained 473 pieces of Olympic medals, to show the world comprehensive strength of our country. Among them, Liaoning athletes won 41 gold medals, ranking first in the country. In the Sixth National Games after the reform and opening up, Liaoning has always been among the top 6 in the country, a total of 294 gold medals, 806.5 medals, are among the forefront of the gold medal list and the medal table. Liaoning province not only transport a large number of sports talent for the country, but also for the country to achieve the strategic goal of competitive sports has made outstanding contributions. In recent years, there are bad tendency of the economy of "landslide" in Liaoning province. In this case, competitive sports in Liaoning Province was able to maintain prosperous, and the implementation of the "foil and strengthen the advantages of the project" strategic measures are inseparable.

In under the influence of the games, the provinces and regions sports authorities were according to the National Games sports setting for the establishment and development of the competitive sports items. This kind of setting and development mode often ignore the actual situation of sports development in all parts of the country, in particular, it can not be based on the unique resources of sports to carry out deeper excavation and greater development. In sports management, there are some outstanding problems in all parts of the world which are including the project investment imbalance, the development of investment is too large, too big to pursue large projects, the backlog of waste, etc.. 
Liaoning Institute of sports technique has the reputation of "gold factory", after the eighth games will be held in the former, Liaoning Province for its funding 34.15 million yuan as special funds for development, also in charge of sports fill the 6.5 million yuan. At the nine games, the delegation of Liaoning has achieved remarkable results, a total of 17 gold medals and 736 points total score.According to statistics, during the nine games, a total investment of 7 million yuan. Among them, there are 3 million 530 thousand yuan for personnel expenditures, accounting for $50.4 \%$ of the total investment, 3 million 220 thousand yuan for the public expenditure, accounting for $46 \%$ of the total investment, there are 250 thousand yuan for research expenditures, accounting for 3.6\% of the total investment. And during the ten games, special funding levels have increased, up to 8 million 360 thousand yuan. Among them, 624 million yuan for senior sports equipment costs accounted for $74.6 \%$ of the total investment; 212 million yuan for training funds accounted for $25.4 \%$ of the total investment. In order to prepare for the 4 year of the Olympic Games, Liaoning province has also increased the intensity of capital investment. In the 2004 Athens Olympics will, for example, in preparing for the Olympic Games last year, for a total investment of 439 million yuan of funds, including gold and red gold athlete total nutrition fee is 350 million yuan, the proportion is as high as $79.7 \%$.

Sports organization and management department has been restricted by the economic level, which also determines the sports management system is bound to adapt to the market economic system. At present, Liaoning Province, as a major province of sports, has a lot of factors that are not conducive to the development of competitive sports in our province. Many managers still use the traditional management mode to carry on the management to the competitive sports in our province, caused by the management of confusion, loss of talent, the consumption of large quantities of money, seriously restricting the development of competitive sports in our province.

In order to solve the above problems, make our province competitive sports toward sports strong province. We must reform the existing management mode, promote the development of competitive sports in our province, so as to adapt to the needs of social development. In the course of development of competitive sports, the whole nation system to play the most vividly, the province of competitive sports in our province is also benefited from the status of this. The whole nation system is a unique successful experience in the development of sports in China. It is the organic unity of China's experience, China Road and the Chinese model, which is confirmed by the practice of sports development in China. From an objective point of view, the practice has fully proved the advantages of the national system, and other countries in the international competitive sports development model is relatively speaking, its performance advantage is very prominent. "National system" is a side of China's competitive sports management system and running mechanism, as Yuan Weimin has repeatedly stressed that the whole nation system is an important factor in China's competitive sports.

Different from the western professional athletes, the high level athletes in our country belong to a special group that enjoys the treatment of the national workers. In the management of athletes and coaches in accordance with the administrative district, the area belongs to the physical cultural administrative department shall enjoy the related personnel, which set the obstacles to the lateral flow of talent, which is not conducive to give full play to the advantages of human resources. For example, our country's plenty of sports talent in the western region, but the level of the coach is limited, and the eastern region was, on the contrary, the lack of open and regular exchange of personnel resources, there is disorder, private transactions, the black box operation flow, which caused a serious loss of national excellent resources. Competitive sports in Liaoning Province to appear serious decline in recent years, the reason is insufficient strength on unpopular project, the personnel loss serious on advantages of the 
project. These problems exist greatly weakened the ability of the triumph. With Liaoning's advantages of the project as an example, judo, athletics, rowing), a considerable part of the membership of Liaoning athletes have played in the provinces of Guangdong, Jiangsu and other Through the research, it is found that the low level of the athletes' income and the loss of effective placement after their retirement are the main factors that cause the loss of the athletes.

\section{Conclusion and Advice}

After the eleven national games of competitive sports in Liaoning slightly has the rise, but inside there are many hidden dangers. The competitive state rebounded slightly, after experienced a 10th of Waterloo in Liaoning Province, and back medals list the top three positions in the 11th National Games, but there exist many hidden dangers to athletics sports reserve talent and to curb the development of strength of competitive sports in Liaoning Province.

Competitive sports in Liaoning Province to appear serious decline in recent years, the reason is insufficient strength on unpopular project, the personnel loss serious on advantages of the project. These problems exist greatly weakened the ability of the triumph. With Liaoning's advantages of the project as an example, judo, athletics, rowing), a considerable part of the membership of Liaoning athletes have played in the provinces of Guangdong, Jiangsu and other Through the research, it is found that the low level of the athletes' income and the loss of effective placement after their retirement are the main factors that cause the loss of the athletes.

Advantages of the project is not good, women's weightlifting, women's judo, the two advantages of the traditional advantages of the Liaoning project is not good, No women participated in the Eleventh National Games gold medal standings.

Is to say it in the track and field in the world, then track and field and swimming two sports foundation in the 11th National Games, Liaoning is also no top players participating.

Whether it is for the active athletes and coaches, as well as the retired athletes and coaches of the security system is a problem, there is no system of security, resulting in brain drain, as well as talent flight.

Through the study of some of the traditional advantages of the project in Liaoning Province, found that many projects are maintained by the veteran. Talent aging problem is serious, the management of coaches and training ideas are gradually out of date, which directly resulted in the poor performance of the Liaoning on the edge of the serious problems. For example, in the Beijing Olympic Games, a large part of the team is composed of old players. The reason is: on the one hand is because veterans who want to achieve join the aspiration of the Olympic Games in their own country; on the other hand is to get the gold medal, and to ensure that indicators completed. Therefore, it causes the team was unable to effectively complete the alternation of old and new interface.

\section{Concluding Remarks}

Developed social economy, sound software and hardware facilities, good sports culture atmosphere for the development of competitive sports in Liaoning province to provide backup protection. Both in the number of training or in the sport, and other provinces compared was the dominant, such as Dalian football, track and field; Shenyang football, gymnastics, weightlifting; Anshan volleyball; Fushun table tennis; Benxi bike; Yingkou water sports; Fuxin basketball and Tieling Judo. From the scale and quantity, the title of Liaoning province's competitive sports province is understandable, in the development of 
competitive sports in China has played a vital role。 Since the reform and opening up, the party and the government from the basic national conditions, put forward the strategy of sports power, and developed a detailed strategic objectives. Our sports work has been carried out in accordance with this goal, and has made great achievements, especially the competitive sports, with the national system advantage, ahead of the development. In the development of competitive sports, Liaoning province has played an important role model.

\section{Acknowledgements}

Fund Project: Project of the humanities and social sciences of the Education Department of Liaoning province (w2015068)

\section{References}

[1] Wu Jinfeng. omparative Study of Xinjiang Ethnic Education for Ethnic Minorities mode with the National Institute of Ethnic Preparatory Training Mode [J]. Xinjiang Normal University (Philosophy and Social Sciences), 2004, 02: 146-151.

[2] Zhou Qiaoyun, The presence of Chinese Teaching Minority Students in southern Liuxiu Ming problems and countermeasures [J]. Kashgar Teachers College, 2014,02: 93-96.

[3] Li Lia. Computer Engineering, Vol. 30 (2004) No 19, p.144-145

[4] Wang Kaili. Mining machinery, Vol. 29 (2008) No 27, p.21-23

[5] Zhang Zhongxi, Sun Jing. Flip teaching mode and its applicability and application strategy of Xinjiang Preparatory Chinese Teaching [J]. Changji University, 2016, 03: 47-52. 